\title{
The Diversity of Repression: Measuring State Repressive Repertoires with Events Data
}

Forthcoming, Journal of Peace Research

Benjamin E. Bagozzi, ${ }^{1}$ Department of Political Science \& International Relations, University of Delaware

Daniel Berliner, Department of Government, London School of Economics

Ryan M. Welch, Department of Political Science and International Studies, University of Tampa

\begin{abstract}
Tactical repertoires of mobilization and repression play an essential role in understanding dynamics of political violence, yet existing quantitative approaches focus primarily on intensities or counts of repressive actions. We focus instead on the diversity of repression, and demonstrate a novel method of measuring repertoires of state repression using event data. We show that more repressive states are likely to employ more diverse repertoires of repression, rather than specializing narrowly in particularly coercive tactics. We demonstrate that, globally, repertoires of state repression are growing less diverse over time. Finally, in the appendix, we model repertoires of repression across countries and over time, finding evidence of broader repertoires during protest and civil war, but narrower under democratic regimes and international human rights treaties.
\end{abstract}

Keywords: Repression, Repertoires, Entropy, Human Rights, Event Data

${ }^{1}$ Corresponding Author. Email: bagozzib@udel.edu 


\section{Introduction}

States employ varying repertoires of repressive tactics. At times states may broaden their repertoires, employing a more diverse and evenly distributed array of tactics; while at other times they may narrow their repertoires, employing a more concentrated array of tactics instead. We suggest a greater empirical focus on this diversity dimension of state repression and offer a novel way to measure it. Our approach enables us to ask entirely new research questions: Is a higher level of repression associated with a few specialized tactics; or a broader repertoire of many tactics? Is the global diversity of repressive repertoires rising, or declining, over time? What country-level factors are associated with more or less diverse repertoires?

While the concept of repertoires is commonplace in discussions of social movements and dissent, few authors have explored it empirically in the context of state repression (Fariss and Schnakenberg, 2014; DeMeritt \& Conrad, 2019). Yet studying state repertoires of repression is crucial given the potential strategic benefits to diversification (Horowitz, Perkoski \& Potter, 2017); the possibilities of substitution across repressive tactics (Ron, 1997, 2003; Demeritt \& Conrad, 2019); and the substantive importance of patterns of violence beyond intensity alone (Gutiérrez-Sanín \& Wood, 2017).

Scholars now know a great deal about what affects levels of state repression. However, we know much less about when and why states choose the breadth of tactics to employ. States may diversify their repertoires of repression to minimize risks and outmaneuver opponents. But they may also limit them; either due to the efficiency of specialization, or when constrained and monitored through domestic and international institutions.

We propose a method to measure the diversity of state repressive repertoires using conflict event data. Such data has been widely analyzed in recent years, but primarily as event 
counts (e.g. Brandt et al., 2011; Hendrix \& Salehyan, 2012) or conflict/cooperation scales (e.g. Goldstein \& Freeman, 1990; Goldstein, 1992; Reuveny \& Kang, 1996). We instead measure the diversity of state repression events across the type of tactic employed. For any given number of state repression events, the diversity of tactics employed ranges from small (all events of a single type) to large (many different types represented in roughly equal proportion).

This measurement strategy proves highly informative. The diversity of state repressive repertoires is strongly and positively associated with existing measures of state repression, such that more repressive states employ more diverse repertoires. However, for many specific countries, our measure exhibits greater responsiveness to key events such as democratic transitions, election violence, or major protests, than do existing standards-based measures of repression. Our measure also has clear advantages over a simple count of repression events, which may be misleading due to the exponential growth in available media sources (Ward et al., 2013) — and thus events over time - that are currently being coded by many large-scale event data projects.

Over the period we study (1996-2016), we demonstrate that the global diversity of repressive repertoires is declining (narrowing) over time, whether measured as an average of country-level repertoires, or as a global repertoire of all repressive events everywhere. However, we do find some evidence of an upward (broadening) turn since 2011. Finally, in the Supplemental Appendix, we also include time-series cross-section models finding that repressive repertoires are broader during protest and civil war, but narrower under democratic regimes and international human rights treaties.

Our approach opens new possibilities in the study of state repression, offering a measurement strategy well-suited to the concept of repressive diversity. We also offer a new use 
of conflict event data, which will become even more useful as new, more detailed event datasets become available with future advances in machine coding resources. Our findings also contribute to recent debates over the changes of repression over time (Posner, 2014; Fariss, 2014;

Cingranelli \& Filippov, 2018; Fariss 2018), complementing Fariss (2014)'s findings by showing that, overall, states are employing less diverse repertoires of repression over time.

In the next section, we review the literature informing our focus on repertoires of repression and their diversity. We then summarize the event data that we use and explain our procedure for producing the measure. We next present key descriptive features of this measure across countries and time, and comparisons with existing measures. Finally, we discuss the promise of this new approach for future research.

\section{Background}

Quantitative human rights and repression scholarship, has spent the last few decades discovering what determines the level of human rights abuse in a country. ${ }^{2}$ The majority of those studies take a 'standards-based' approach, treating the outcome of interest as a latent concept reflecting the standard of human rights protection; or conversely of state repression. This approach avoids many concerns that arise with event-based data, such as uneven availability of information and the conceptual difficulty of aggregation across different event types and scales. Others measure and analyze repressive events directly (e.g. Harff, 2003; Eck \& Hultman, 2007; Sullivan, 2016).

Regardless of the type of data used, nearly all research has implicitly sought to address whether there is more or less repression, or a better or worse standard of respect for human rights. Few have explicitly conceptualized, let alone measured, more complex dimensions of

${ }^{2}$ For a recent review of this literature see Moore \& Welch (2015). 
state repression, such as the diversity of state repressive repertoires, despite theoretical reasons to believe that diversifying one's repressive tactics hold several advantages such as minimizing risk (Kydd \& Walter, 2006) and innovating around obstacles (Chakrabarti, 2014).

This lack of attention to the diversity dimension of state repression is curious given that scholars often write about repertoires from the other side of the repression-dissent nexus. Tilly (1986: 2) conceptualized repertoires of contention as the set of means at a challenger's disposal for making claims. These repertoires 'provide templates for interaction, bases for collective memory, and switchpoints for collective struggle' (Tilly, 2003: 46). In this literature, while challengers choose from potentially rich palettes of contentious tactics, the state's reactions include only prescription, toleration, or forbidding of challenger behavior. Other scholars have used the repertoires of contention concept, most attributable to Tilly (Tarrow, 2008), to fruitfully explore social movements and contentious politics (e.g. Tarrow, 1998; Rolfe, 2005; Wada, 2012).

Researchers studying violent contentious challenges have also studied factors that shape the repertoires of armed actors including both internal organizational dynamics (Hoover-Green, 2016; Gutiérrez-Sanín \& Wood, 2017) or external pressures (Horowitz, Perkoski \& Potter 2017). Here, Gutiérrez-Sanín \& Wood (2017) argue patterns of violence should be studied not only through their frequency, but also their repertoires. ${ }^{3}$ They note that repertoires do not necessarily vary in correspondence to the intensity of violence, suggesting a hypothetical armed organization for which 'the repertoire might be narrower, but the overall level of violence more severe, if the organization decided to exterminate some population rather than displace, torture, and rape them as before' (23).

\footnotetext{
${ }^{3}$ They also stress the potential importance of targeting and techniques.
} 
Despite the past work on repertoires of both non-violent and violent contention, few scholars studying state violence towards those contenders have directly considered the idea. This despite McCormick \& Mitchell (1997)'s warning ${ }^{4}$ against treating repression as a unidimensional concept.

Although Cingranelli \& Richards (1999) made available data on human rights abuses disaggregated into different tactics, only a few studies leverage this granularity. DeMeritt \& Conrad (2019) find international shaming leads to tactic substitution, echoing arguments made earlier by Ron (1997, 2003) and Rejali (2009). Fariss and Schnakenberg (2014) use network analysis to examine complementary and substitutive relationships among abuse types, finding the former to be far more frequent than the latter. ${ }^{5}$

While these scholars acknowledge different types of repression in their work, none offer a systematic way to measure diversity as an additional dimension of repression. We seek to advance the study of repressive repertoires by doing just that. Gutiérrez-Sanín \& Wood (2017) note concern over whether researchers can observe repertoires, given problems of data availability and conceptual problems of choosing the level of granularity with which to disaggregate violence. Yet they propose that these problems may actually be more easily overcome than similar challenges in measuring the frequency of violence itself. While their solution is to study repertoires using detailed data from one country, compiled across multiple sources, we seek to develop a more general approach suitable to analysis at a global scale.

\footnotetext{
4 Davenport (2007: 3) later echoed the sentiment when he called for more research acknowledging that "governments select from the full repertoire of coercive activities."

${ }^{5}$ We remain agnostic in this debate. Relatedly, states may build toward more violent actions in a sort of lexical hierarchy (we thank an anonymous reviewer for this point). Even so, diversity of repression could decrease as states specialize; stay the same as they maintain a similar number of tactics further up the violence scale; or increase as they continue using the original tactics and add more violent ones. Our measure could be used in future studies to empirically evaluate these potential progressions.
} 
Drawing from Gutiérrez-Sanín \& Wood (2017: 24), we conceptualize a repertoire of repression as the state's 'subset of all possible forms of violence against civilians in which it regularly engages. ${ }^{6}$ That is, '[r]epertoires can be wide (many forms) or narrow (e.g. only killing)' (Gutiérrez-Sanín \& Wood, 2017: 24). Following Hoover-Green (2016: 619), we do so by focusing on the 'relative proportions' of different forms of violence.

\section{Developing the Measure}

To empirically assess the diversity of repressive repertoires across states, we derive a series of information-theoretic entropy measures from a global sample of finely disaggregated political event data. Political event data denote 'who did what to whom (and where/when)' for a wide variety of event action types, including public protests, offers of mediation, suicide bombings, provisions of asylum, destructions of property, impositions of curfews, assassinations, violations of cease-fires, or mass expulsions. Alongside these action types, extensive actor designations allow analysts to examine state actors such as elected government officials, members of the judiciary, military actors, the police, and intelligence agents. Categories for nonstate actors, equally diverse, can encompass civilians, refugees, businesses, unions, media, religious and ethnic groups, and criminals. To obtain this level of detail, event data are increasingly coded from local and international news(wire) reports with the aid of machines.

The granularity in actions, actors, and spatio-temporal scales has led to the use of event data across many conflict research tasks encompassing both predictive (e.g. Brandt et al., 2011; Chiba \& Gleditsch, 2017) and explanatory (e.g. Hendrix \& Salehyan, 2012) aims. For our

\footnotetext{
${ }^{6}$ Those that are instead interested in a state's latent, or possible, repressive tactics may wish to consider the V-Dem project (Coppedge et al., 2020).
} 
anticipated measures, we consider one specific global event data source: the Integrated Crisis Early Warning System (ICEWS) dataset (Boschee et al., 2015). ICEWS is a machine-coded event dataset that includes intrastate and interstate interactions involving every country in the world aside from purely domestic US events, 1995-present. ${ }^{7}$ Coded from multilingual news sources, it contains fields for action type, source/target actor, date, source/target country, geolocation, and news source, among other variables - making it one of the most comprehensive and accurate event datasets available (D’Orazio et al., 2011; Ward et al., 2013).

ICEWS designates source/target actors by 'sectors.' These sectors extend the CAMEO source/target actor hierarchy originally developed by Schrodt et al. (2009). We use these sectors to subset the ICEWS data to only domestic events involving government source actors and civilian target actors. Given our interest in repression, we next subset our retained events to encompass only those event actions considered 'material conflict' — while also omitting CAMEO protest events. ${ }^{8}$ We then applied 'one-a-day' filtering to minimize duplicates of the same event in our ICEWS event data, before summing all remaining events to the country-year-action-level for the years 1996-2016. The Supplemental Appendix provides further details on, and robustness assessments of, these data aggregation decisions.

Together, these steps generated country-year repression event counts for every (non-US) country of the world during the years 1996-2016, disaggregated according to 30 CAMEO event categories. We report event frequencies for each repression category, and the proportion of all events that fall within each repression category, in Table A.I of the Supplemental Appendix.

\footnotetext{
${ }^{7}$ Our ICEWS data end in 2016 due to data availability at the time of analysis. We also omit the first year of the ICEWS data, 1995, from some analyses due to the lagging of a number of other variables of interest. 8 Protest events primarily encompass citizen actions targeting the government; thus we exclude them.
} 
We represent all repression events in each country-year as a probability distribution over these thirty different categories of events. The measure is much less sensitive to the overall count of events - it reflects instead only the relative proportions of different types of events. From this distribution, we then calculate the entropy of repression for each country using the formula:

$$
-\sum_{i=1}^{n} p_{i}\left(\log _{2} p_{i}\right)
$$

where $n$ is the number of different event categories present in each country-year, and $p$ is the proportion of all events in that country-year comprising each category. Entropy can be calculated with a logarithm of any base, but using base two results in a value measured in bits. ${ }^{9} \mathrm{~A}$ coin flip with even probabilities thus has entropy of one, while $p=(1 / 4,1 / 4,1 / 4,1 / 4)$ has entropy of two, and $p=(1 / 8,1 / 8,1 / 8,1 / 8,1 / 8,1 / 8,1 / 8,1 / 8)$ has entropy of three.

This information-theoretic measure, known as Shannon's H, captures how much information can be learned about a distribution from a single randomly drawn event (Shannon (1948). ${ }^{10}$ In a low-entropy system, any given event is likely to be more informative than in a high-entropy system. Compared with other measures of diversity, such as an inverse Herfindahl index, entropy is less skewed and better suited for precision at high and low levels (Boydstun et al., 2014). This enables clearer differentiation among states with either very high or very low values of diversity in repressive repertoires, whereas Herfindahl indices tend to compress values at these extremes into less nuanced groupings. ${ }^{11}$

\footnotetext{
${ }^{9}$ This is advantageous in that bits are (1) a valid measure for time series analysis, (2) provide a principled and nonambiguous means for transforming information across distinct (event) sources into consistent units, and (3) represent a common and extendable unit of measurement in information theory (Hilbert and López 2012: 947-948).

${ }^{10}$ DeDeo (2018) offers an intuitive introduction.

${ }^{11}$ We also illustrate this via comparisons and robustness assessments involving entropy and an inverse Herfindahl index in our Supplemental Appendix.
} 
Another useful feature of entropy is consistency under coarse-graining. As DeDeo et al. (2013: 2248) explain, 'if two outcomes are grouped, then the uncertainty is the uncertainty of the more coarse-grained description, plus the (weighted) uncertainty of outcomes from the grouped category.' This is desirable for measures of (repressive) repertoires derived from political event data given that the underlying event data inputs for such measures often have different (nested) levels of granularity in available event categories — such as the different levels of CAMEO event categories discussed in the Supplemental Appendix. In the Supplemental Appendix, we demonstrate our repression entropy measure's robustness to different levels and choices of coarse-graining in the repression event categories employed.

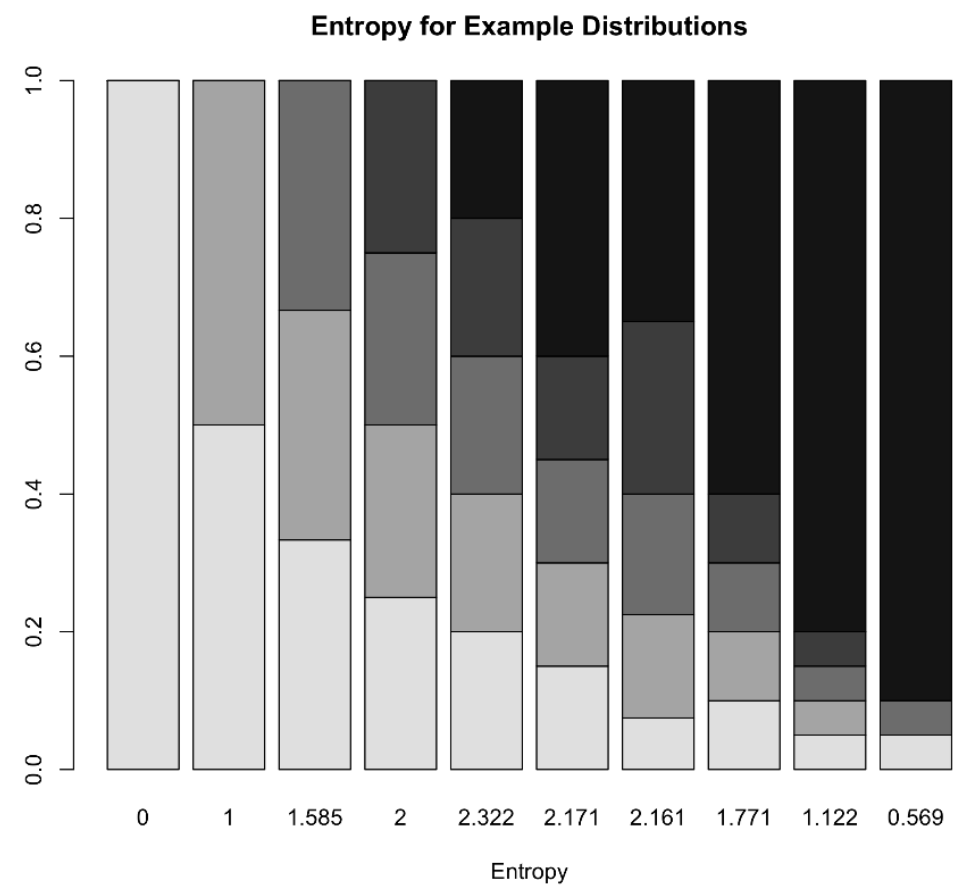

Figure 1. Example distributions with associated values of entropy

Figure 1 illustrates the entropy values for a series of example distributions. As the distribution has more possible outcomes, entropy increases, but it falls as the distribution becomes less even and more concentrated on one or a few possible outcomes. One limitation of 
this measure is that it requires a sufficient number of events to be observed in the first place. An entropy of two, based on fifty events each of two different types, is more reliable than an entropy of two based on one event each of two types. Hence, in some analyses we restrict the sample to countries with at least some threshold number of repression events observed - most often ten.

\section{Comparisons with Existing Measures of Repression}

How does the entropy of state repressive repertoires relate to the level of repression? Do repressive states forgo most tactics to perform highly repressive actions in which they specialize? Or do repressive states diversify their repressive repertoires? We find very clear evidence of the latter - more repressive governments employ more diverse repertoires. In this section, we present illustrative results to show this relationship. ${ }^{12}$ Figure 2 shows two plots, both with Fariss' (2014) human rights scores on the $\mathrm{x}$-axis (but reversed such that higher values reflect more repression) in order to capture existing standards-based measures of the level of repression. The first panel shows the logged count of repressive events on the y-axis, while the second shows our new entropy measure. ${ }^{13}$ In both panels, the placement of each country reflects averaged values over the entire observed period since 1996.

\footnotetext{
12 In the Supplemental Appendix, we demonstrate this relationship holds when controlling for covariates often included in repression research.

${ }^{13}$ We present equivalent plots to Figure 2 that instead use a Goldstein scale in place of our raw counts of repressive events in the Supplemental Appendix, reaching comparable conclusions to those discussed here.
} 

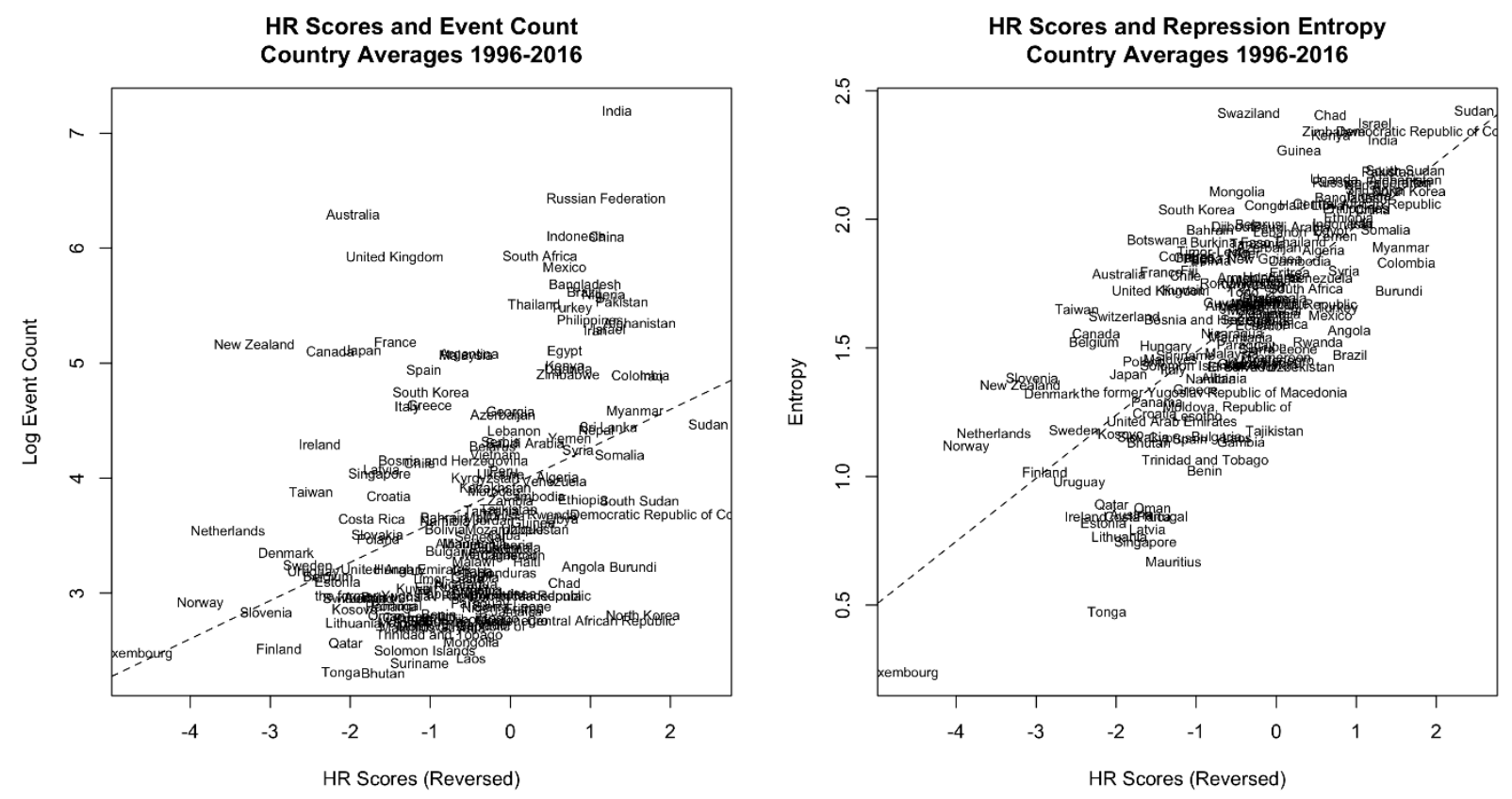

Figure 2. Comparison between existing repression measure, count of state repressive events, and entropy of state repressive events. Each point represents the averages for each country across all observed years.

The first panel shows that, while a positive relationship exists between the level of repression and the count of repressive events, a great deal of unrelated variation remains. Some highly repressive countries have very low event counts, such as North Korea and the Central African Republic, suggesting limitations stemming from lack of access or lack of interest by the global media. This relationship also comports with the 'more murder in the middle' theory in which very autocratic governments do not actively repress because citizens do not dissent for fear of repercussions (Regan \& Henderson, 2002). On the other hand, some much less repressive countries register very large event counts - such as Australia and the United Kingdom - most likely reflecting much greater media attention.

The second panel, however, illustrates a very strong correspondence between the level of repression and the diversity of repressive repertoires, despite these two measures' entirely 
distinct sources and methods of construction. ${ }^{14}$ North Korea and the Central African Republic even appear almost precisely on the line of best fit, despite their relatively low observed event counts. Yet there is also interesting variation around the line of best fit, demonstrating that the diversity of repression remains a distinct concept. Among more repressive countries, some employ more diverse repertoires - such as Israel and Zimbabwe - while others employ less diverse repertoires - such as Burundi and Turkey. Similarly, among less repressive countries, some employ more diverse repertoires - such as Germany and Slovenia - while others employ less diverse repertoires - such as Portugal and Qatar. In the Supplemental Appendix, we find meaningful relationships explaining this variation, while controlling for existing standards-based measures.

We next compare the entropy of repression to both the count of repressive events, and to two existing measures (Fariss [2014] and the Political Terror Scale [Gibney et al., 2019]), for a selection of countries in order to illustrate their relative patterns over time. Entropy generally aligns well with existing measures, even where event counts do not. For example, Figure 3 suggests that the event count for India rises dramatically over time, even though existing repression measures suggest relative stability or even a decrease. The entropy of repression, in turn, remains roughly stable over time as well. A similar pattern appears for many other countries, with event counts increasing in ways that do not reflect the consensus view of repression trends, whereas the diversity of repression exhibits very different—and much more intuitive-patterns over time.

\footnotetext{
${ }^{14}$ Although Fariss' (2014) Human Rights Scores incorporate both standards-based and events-based data sources, the event sources used are not daily conflict events data like ICEWS, but rather measure the annual presence or absence of major episodes like genocides, mass repressive events, and killings and executions.
} 
India:

Repression Entropy

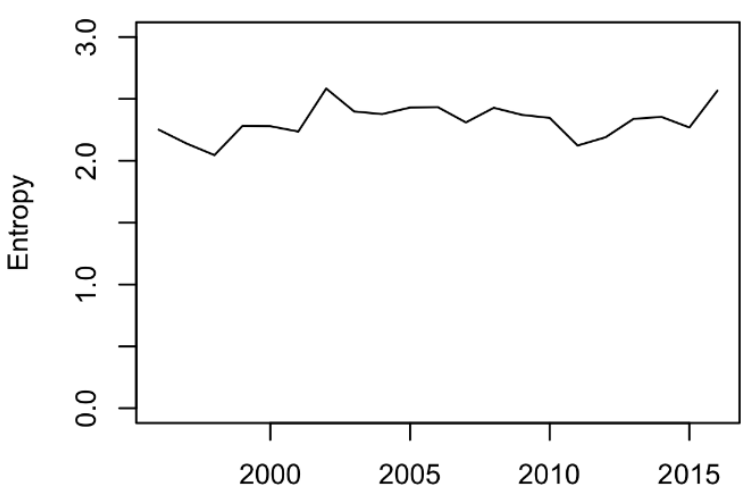

India:

Human Rights Score (Reversed)

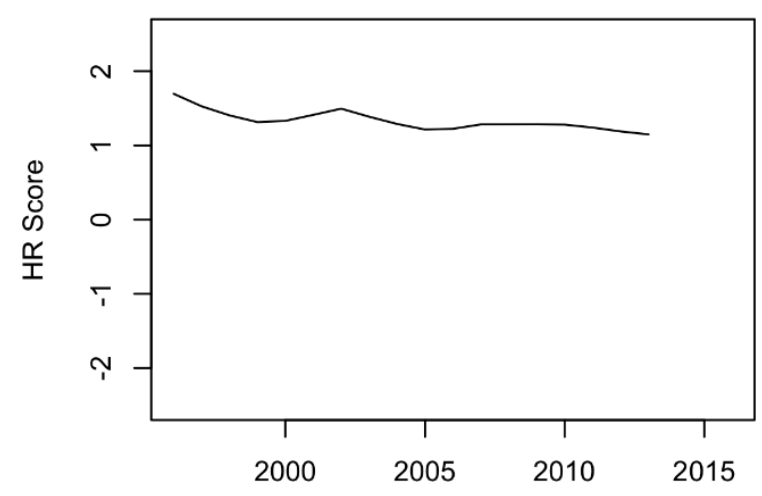

India:

Log Repression Event Count

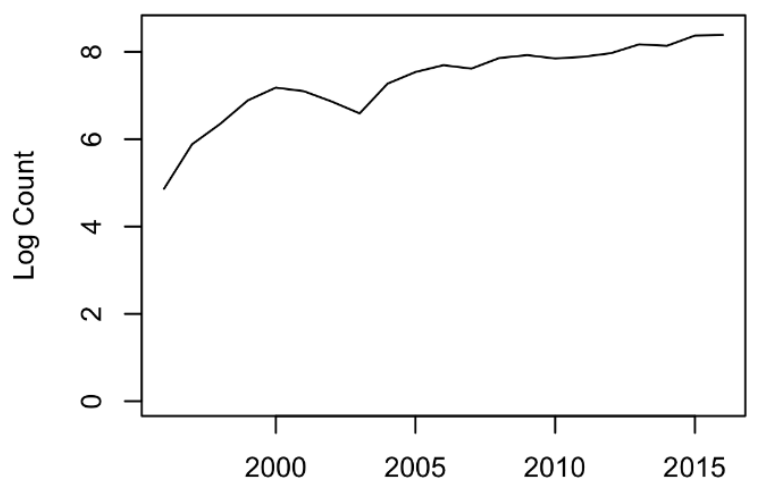

India:

Political Terror Scale

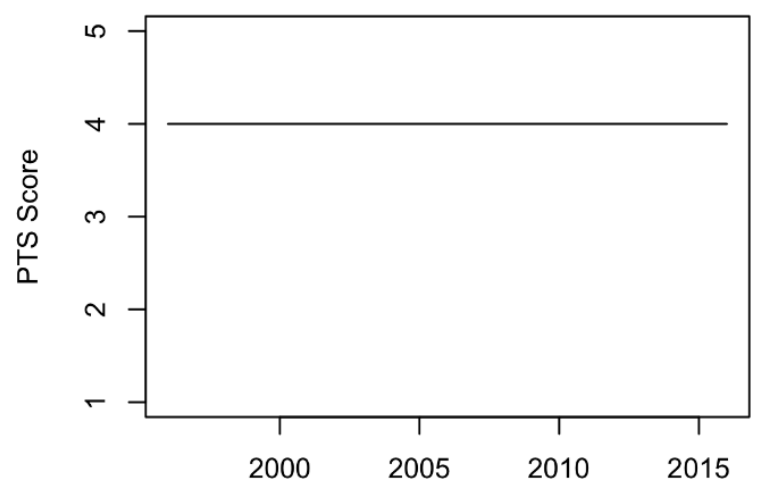

Figure 3. Comparison of four measures for India, 1996-2016 (only through 2013 for Human

\section{Rights Scores).}

In some cases, the entropy of repression even seems to offer substantially more information than existing measures, particularly around key events such as democratic transitions, major protests, or elections. Figure 4 shows data for Yugoslavia/Serbia, where a democratic transition followed the downfall of Milosevic's repressive regime in October 2000. The event count alone would suggest that repression remained as intense after the transition as it had been in the late 1990s, which is clearly incorrect. Yet the entropy of repression falls 
dramatically from 2000-2001 and remains at a much lower level. In fact, the diversity of repressive repertoires appears to respond much more rapidly to the transition than do existing standards-based measures.
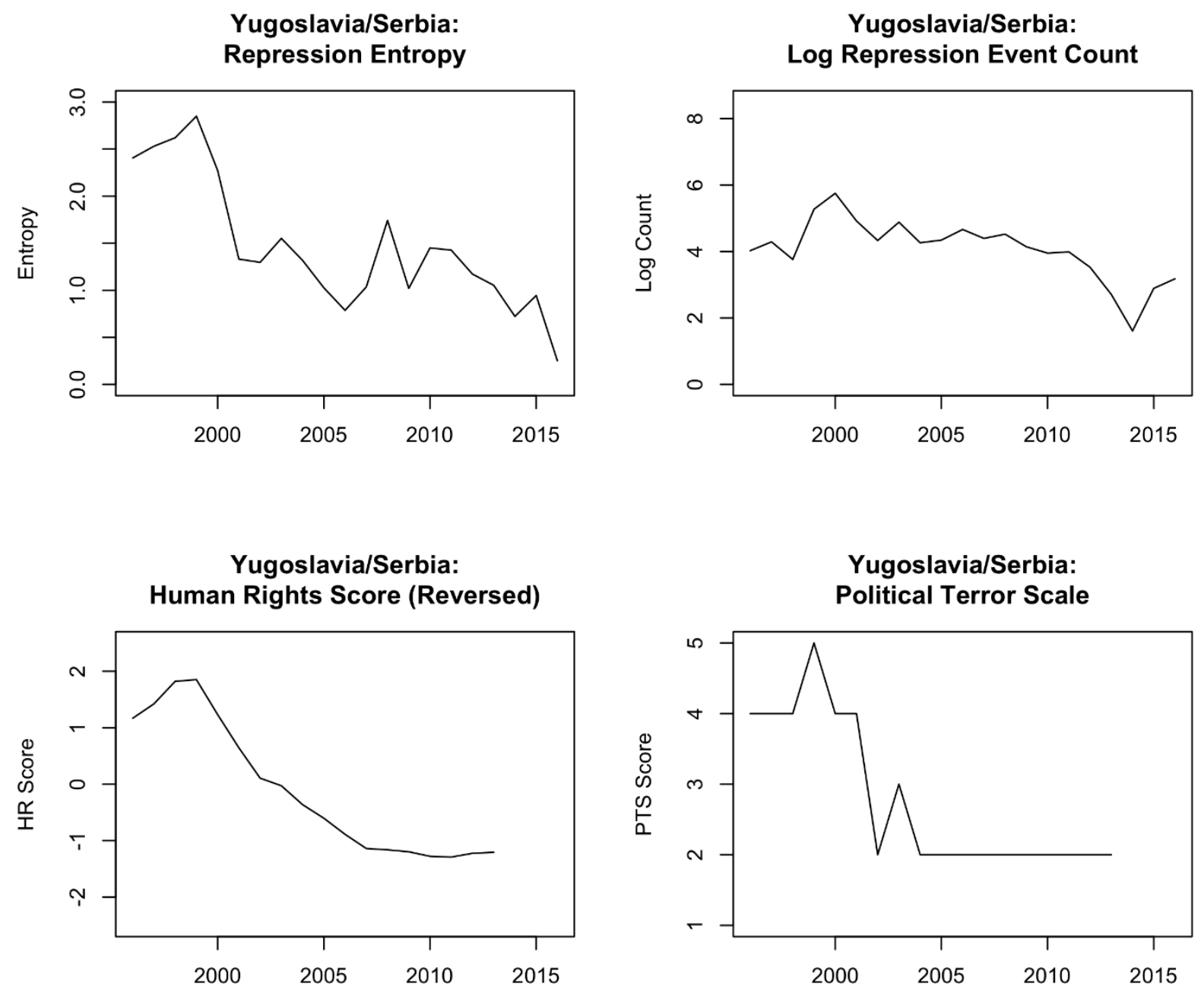

Figure 4. Comparison of four measures for Serbia, 1996-2016 (only through 2013 for Human

\section{Rights Scores)}

We present several similar figures for other countries in Figures A5-A11. The diversity of state repressive repertoires jumps sharply in 2013 in both Turkey and Brazil, where major protest movements challenged both governments in that year. Yet an analysis using either event counts 
or standards-based measures would identify a much more limited or delayed state response, or even none at all. Similar figures for Kenya and Iran also suggest increases in the diversity of state repressive repertoires during or following highly contested elections and ensuing protest and violence. Entropy increases sharply in Kenya in 2008 (after the 12/27/2007 presidential election which resulted in substantial conflict and repression) and increases in Iran's 2005 and 2009 presidential election years. These figures illustrate the value of studying the diversity of repressive repertoires as a distinct concept.

\section{Are Repertoires of Repression Growing More or Less Diverse over Time?}

Recent debates have focused on the seemingly simple, but methodologically complex, question of whether or not human rights are improving over time (Clark \& Sikkink, 2013; Posner, 2014; Fariss, 2014; Sikkink, 2017; Cingranelli \& Filippov, 2018; Fariss, 2018). Our approach enables us to ask a parallel question: Have state repertoires of repression grown more or less diverse over time?

Given that we observe individual repressive events worldwide for the period 1996-2016, we consider two ways to approach this question. First, we compute annual average values of entropy across all country-year-level observations. This, however, requires us to decide how to treat country-years with small numbers of observed events. Entropy estimates may be unreliable for country-years with relatively few events and cannot be computed at all where no events are observed. We thus set varying thresholds to define the sample in which to evaluate changing diversity of state repertoires over time.

Second, we ignore countries altogether, and simply compute a global value of entropy across all state repression events in each year, regardless of where in the world they take place. 
This avoids the necessity of defining the sample of countries, as the entropy of all repressive events in the world comprise a single annual observation. However, this also has the effect of weighting countries with large numbers of observed events - like Australia, China, India, and Russia - more heavily than countries with fewer observed events, whereas the first approach weights each country equally, conditional on its inclusion in the sample.
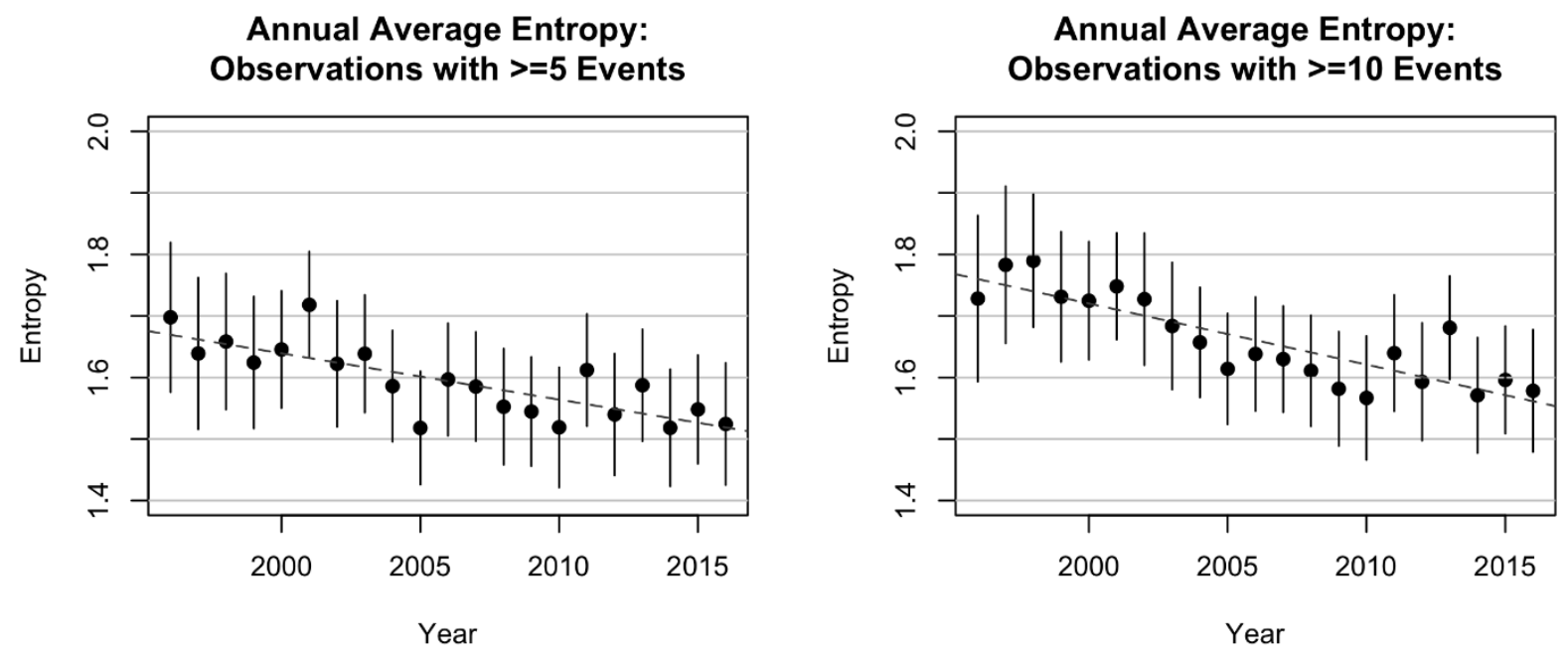

Annual Average Entropy: Countries with Consistently $>=5$ Events

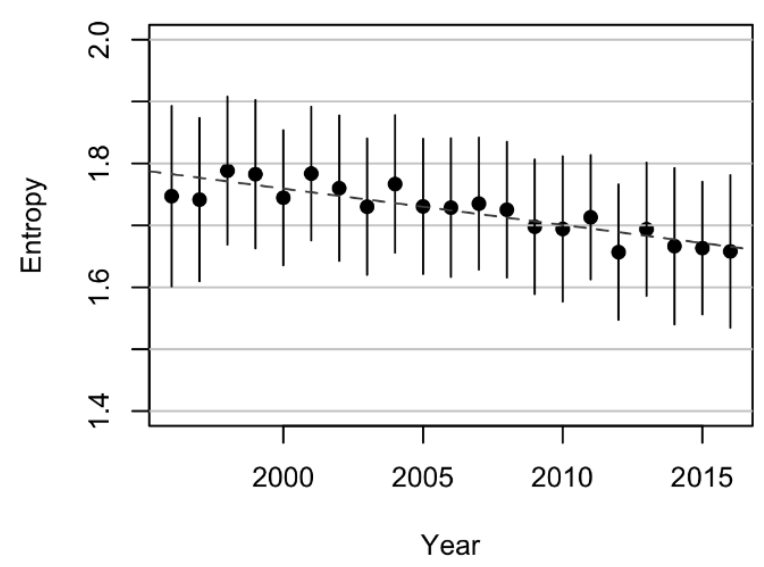

Annual Average Entropy: Countries with Consistently > $=10$ Events

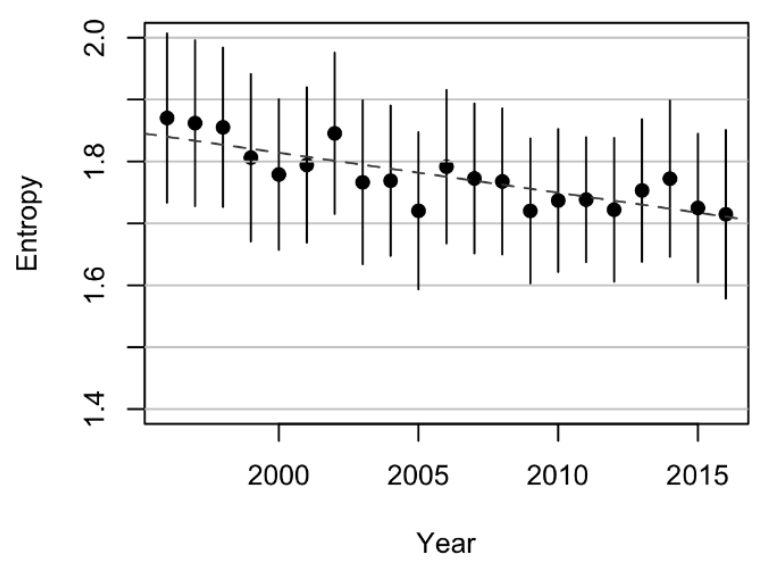

Figure 5. Changing average diversity of repression over time. Each panel employs a different sample of countries, limited either by the number of observed events, or to a stable set of 
countries that are consistently observed with a given number of events. Vertical bars reflect 95 percent confidence intervals.

Figure 5 shows the first approach, with annual average values of entropy computed across country-years. The top row of panels includes only observations with at least five, and at least ten, observed events each year. The bottom row limits the sample to those countries which consistently meet the five and ten event thresholds over their time-series. In all cases, the figures show a declining entropy over time, consistent with state repertoires of repression growing narrower, not broader. In some plots, the decline levels off in years since roughly 2010 .

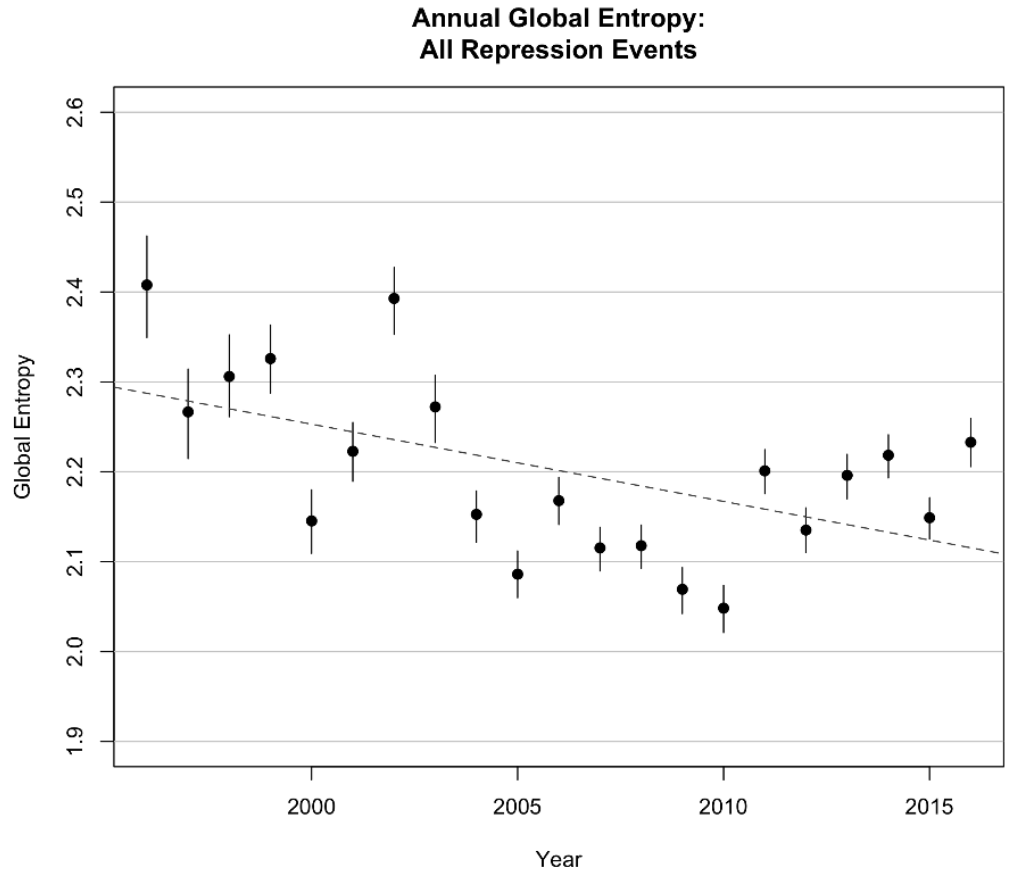

Figure 6. Changing global diversity of repression over time, based on all state repressive events in each year, regardless of country. Vertical bars reflect 95 percent confidence intervals, based on a bootstrap resampling (with replacement) from all events each year.

In Figure 6, we show the second approach, computing a global value of entropy across all repressive events in each year, regardless of the state responsible. Here, the confidence intervals 
come from a bootstrap, resampling 1,000 times with replacement from the observed events each year. This figure is also consistent with a declining entropy over time, as shown by the line of best fit. However, there is a clear shift since 2011, with entropy values higher than the low point of 2010, though not as high as in the late 1990s. This difference in findings from the first approach is attributable to the different ways of weighting events, with the first approach weighting each country equally, and the second approach instead weighting each repressive event equally, thereby giving more emphasis to high-event-volume countries.

Nonetheless, despite the slightly different patterns since 2011, both approaches suggest a broad global pattern by which the diversity of state repressive repertoires has declined over time. Further, we investigate potential determinants of this global decline at the country-year level in the Supplemental Appendix. By including a time trend in regression models of the entropy of state repression, we confirm a statistically significant negative decline in the diversity of state repertoires of repression over time. We further find evidence suggesting that the global decline may be attributable to the expansion of institutions that constrain and inform, in the form of democratic regimes and international human rights treaties.

\section{Conclusion}

This article develops a novel means of measuring the diversity of states' repressive repertoires. We do so by applying an information-theoretic entropy measure to ICEWS-derived political event data. For any given number of state repression events, we find that our resultant entropy measure of state repressive tactics ranges from small (narrow) to large (broad), and is highly informative. This diversity-based measure of state repressive repertoires is strongly and positively associated with existing measures of state repression while remaining a distinct 
concept. It also exhibits greater responsiveness to key external events than do existing measures. This suggests not only the validity of our measure, but its advantages for detecting key shifts in state repressive behaviors, including within tasks related to 'conflict early warning' and conflict forecasting.

Over the period we study, we also determine that the global diversity of repressive repertoires is declining (narrowing) over time, whether measured as an average of country-level repertoires, or as a global repertoire of all repressive events everywhere. Within the context of recent debates over the direction of changes in global repression over time (e.g. Posner, 2014; Fariss, 2014; Cingranelli \& Filippov, 2018; Fariss, 2018), these findings thereby complement those of Fariss (2014) with a distinct concept, data source, and measurement approach. At the same time, we do find some evidence of an upward (broadening) turn in global repressive repertoires since 2011. Our Supplemental Appendix's analyses suggest that this post-2011 global trend could relate to factors such as democratic reversals or eroding international norms. Future research should explore this further, as well as (i) the complementarity vs. substitutability of repression tactics and (ii) whether states shift their repertoires in response to external pressure from the international human rights regime or from domestic dissent.

Our novel use of conflict events data also has the potential to improve event data analyses and forecasting efforts in ways that extend beyond the study of state repression. As noted above, most contemporary event data aggregation approaches rely on counts of event type(s). However, the ever-expanding pool of available news media for event coding often ensures that count-based aggregations of event data must either ignore these new sources of event information or accept an increasing count of events over time, even where on-the-ground event levels have remained 
constant. Our measure is less sensitive to these latter coding effects and thus is likely to be less biased for analyses of event data over time and within the most prominent global event datasets.

Finally, conceptualizing and measuring repressive repertoires offers a tool for evaluating the international human rights regime's ultimate goal of reducing repression. As this regime gradually takes certain tactics off the table through international norms and monitoring, repressive states can either innovate or choose from a shrinking repertoire of tactics. Our results suggest that, on average, repressive states are choosing from fewer tactics over time. This approach may enable the detection of possible innovation by repressive states in the future - a useful tool in the fight for human rights.

Replication Data: Replication data, analysis and formatting scripts, and an online appendix can be found at http://www.prio.org/jpr/datasets

Acknowledgements: This article was previously presented at the 2018 International Studies Association (ISA) Annual Meeting and the University of Minnesota Institute of Statistics and Its Applications Workshop. We would like to thank Scott Gates, two anonymous reviewers, Mary Anderson, Snigdhansu Chatterjee, John Freeman, Kevin Fridy, Jonathan Lewallen, William Myers, Phil Schrodt, and Nils Weidmann for helpful comments.

Funding: Bagozzi's contribution is partly based upon work supported by the National Science Foundation under Grants No. SBE-SMA-1539302 and DMS-1737865. Berliner and Welch's contributions were partially supported by the School of Politics and Global Studies, Arizona State University. 


\section{References}

Boschee, Elizabeth; Jennifer Lautenschlager, Sean O’Brien, Steve Shellman, James Starz \& Michael Ward (2015) ICEWS coded event data. Harvard Dataverse, V22. (https://doi:10.7910/DVN/28075).

Boydstun, Amber E.; Shaun Bevan \& Herschel F Thomas (2014) The importance of attention diversity and how to measure it. Policy Studies Journal 42(2):173-196.

Brandt, Patrick T; John R Freeman \& Philip A Schrodt (2011) Real time, time series forecasting of inter- and intra-state political conflict. Conflict Management and Peace Science 28(1):41-64.

Chakrabarti, Abhirup (2014) Organizational adaptation in an economic shock: The role of growth reconfiguration. Strategic Management Journal 36(11):1717-1738.

Chiba, Daina \& Kristian Skrede Gleditsch (2017) The shape of things to come? Expanding the inequality and grievance model for civil war forecasts with event data. Journal of Peace Research, 54(2):275-297.

Cingranelli, David \& Mikhail Filippov (2018) Problems of model specification and improper data extrapolation. British Journal of Political Science 48(1):273-274.

Cingranelli, David \& David L Richards (1999) Measuring the level, pattern, and sequence of government respect for physical integrity rights. International Studies Quarterly 43(2):407-417.

Clark, Ann Marie \& Kathryn Sikkink (2013) Information effects and human rights data: Is the good news about increased human rights information bad news for human rights measures? Human Rights Quarterly 35(3):539-568.

Coppedge, Michael; John Gerring, Carl Henrik Knutsen, Staffan I Lindberg, Jan Teorell, David 
Altman, Michael Bernhard, M Steven Fish, Adam Glynn, Allen Hicken, Anna Luhrmann, Kyle L Marquardt, Kelly McMann, Pamela Paxton, Daniel Pemstein, Brigitte Seim, Rachel Sigman, Svend-Erik Skaaning, Jeffrey Staton, Steven Wilson, Agnes Cornell, Nazifa Alizada, Lisa Gastaldi, Haakon Gjerløw, Garry Hindle, Nina Ilchenko, Laura Maxwell, Valeriya Mechkova, Juraj Medzihorsky, Johannes von Römer, Aksel Sundström, Eitan Tzelgov, Yi-ting Wang, Tore Wig \& Daniel Ziblatt (2020) V-Dem dataset v10. Varieties of Democracy (V-Dem) Project. (https://doi.org/10.23696/vdemds20).

Davenport, Christian (2007) State repression and political order. Annual Review of Political Science 10:1-23.

DeDeo, Simon (2018) Information theory for intelligent people. (http://tuvalu.santafe.edu/ simon/it.pdf).

DeDeo, Simon; Robert XD Hawkins, Sara Klingenstein \& Tim Hitchcock (2013) Bootstrap methods for the empirical study of decision-making and information flows in social systems. Entropy 15(6):2246-2276.

DeMeritt, Jacqueline HR \& Courtenay R Conrad (2019) Repression substitution: Shifting human rights violations in response to UN naming and shaming. Civil Wars 21(1):128152.

Eck, Kristine \& Lisa Hultman (2007) Violence against civilians in war. Journal of Peace Research 44(2):23-246.

Fariss, Christopher J (2014) Respect for human rights has improved over time: Modeling the changing standard of accountability. American Political Science Review 108(2):297-318.

Fariss, Christopher J (2018) Are things really getting better? How to validate latent 
variable models of human rights. British Journal of Political Science 48(1):275-282.

Fariss, Christopher J. \& Keith E Schnakenberg (2014) Measuring mutual dependence between state repressive actions. Journal of Conflict Resolution 58(6):1003-1032.

Gibney, Mark; Linda Cornett, Reed Wood, Peter Haschke, Daniel Arnon, Attilo Pisanò \& Gary Barrett (2019) The political terror scale 1976-2018. (http://www.politicalterrorscale.org).

Goldstein, Joshua S \& John R Freeman (1990) Three Way Street: Strategic Reciprocity in World Politics, Chicago, IL: University of Chicago Press.

Goldstein, Joshua S (1992) A conflict-cooperation scale for WEIS events data. Journal of Conflict Resolution 36(2):369-385.

Gutiérrez-Sanín, Francisco \& Elisabeth Jean Wood (2017) What should we mean by 'pattern of political violence'? Repertoire, targeting, frequency, and technique. Perspectives on Politics 15(1):20-41.

Harff, Barbara (2003) No lessons learned from the Holocaust? Assessing risks of genocide and political mass murder since 1955. American Political Science Review 97(1):57-73.

Hendrix, Cullen S \& Idean Salehyan (2012) Climate change, rainfall, and social conflict in Africa. Journal of Peace Research. 49(1):35-50.

Hilbert, Martin \& Priscila López (2012) How to measure the world's technological capacity to communicate, store, and compute information part II: Measurement unit and conclusions. International Journal of Communication 6:936-955.

Hoover-Green, Amelia (2016) The commander's dilemma: Creating and controlling armed group violence. Journal of Peace Research 53(5):619-632.

Horowitz, Michael C; Evan Perkoski \& Philip BK Potter (2017) Tactical diversity in 
militant violence. International Organization 72:139-171.

Kydd, Andrew H \& Barbara F Walter (2006) The strategies of terrorism. International Security 31(1):49-80.

McCormick, James M \& Neil J Mitchell (1997) Human rights violations, umbrella concepts, and empirical analysis. World Politics 49(4):510-525.

Moore, Will H \& Ryan M Welch (2015) Why do governments abuse human rights? In Robert Scott \& Stephan Kosslyn (eds) Emerging Trends in the Social and Behavioral Sciences. Hoboken, NJ: John Wiley \& Sons, Inc, 1-16.

Posner, Eric A (2014) The Twilight of Human Rights Law. Oxford: Oxford University Press. Regan, Patrick M \& Errol A Henderson (2002) Democracy, threats, and political repression in developing countries: Are democracies internally less violent? Third World Quarterly 23(1):119-136.

Rejali, Darius (2007) Torture and Democracy. Princeton, NJ: Princeton University Press.

Reuveny, Rafael \& Heejoon Kang (1996) International trade, political conflict/cooperation, and granger causality. American Journal of Political Science 40(3):943-970.

Rolfe, Brett (2005) Building an electronic repertoire of contention. Social Movement Studies $4(1): 65-74$.

Ron, James. (1997) Varying methods of state violence. International Organization 51(2):275300.

Ron, James (2003) Frontiers and Ghettos: State Violence in Serbia and Israel. Berkeley, CA: University of California Press.

Schrodt, Philip A; Deborah J Gerner \& Omur Yilmaz (2009) Conflict and mediation event 
observations (CAMEO): An event data framework for a post-Cold War world. In Bercovitch, Jacob \& Scott Sigmund Gartner (eds) International Conflict Mediation: New Approaches and Findings. New York: Routledge, 287-304.

Shannon, Claude E (1948) A mathematical theory of communication. Bell System Technical Journal 27(July):379-423.

Sikkink, Kathryn (2017) Evidence for Hope: Making Human Rights Work in the 21st Century. Princeton, NJ: Princeton University Press.

Sullivan, Christopher M (2016) Undermining resistance: Mobilization, repression, and the enforcement of political order. Journal of Conflict Resolution 60(7):1163-1190.

Tarrow, Sidney (1998) Power in Movement: Social Movements and Contentious Politics. New York: Cambridge University Press.

Tarrow, Sidney (2008) Charles Tilly and the practice of contentious politics. Social Movement Studies 7(3):225-246.

Tilly, Charles (1986) The Contentious French. Cambridge, MA: Harvard University Press.

Tilly, Charles (2003) The Politics of Collective Violence. New York: Cambridge University Press.

Wada, Takeshi (2012) Modularity and transferability of repertoires of contention. Social Problems 59(4):544-571.

Ward, Michael D; Andreas Beger, Josh Cutler, Matthew Dickenson, Cassy Dorff \& Ben Radford (2013) Comparing GDELT and ICEWS event data. Working Paper. (https://benradford.github.io/images/publications/GDELTICEWS.pdf) 


\section{Author Bios:}

Benjamin E. Bagozzi, b. 1983, PhD in Political Science (Pennsylvania State University, 2013); Associate Professor of Political Science \& International Relations, University of Delaware.

Daniel P. Berliner, b. 1985, PhD in Political Science (University of Washington, 2012); Associate Professor of Political Science and Public Policy, London School of Economics.

Ryan M. Welch, b. 1982, PhD in Political Science (Florida State University, 2015); Assistant Professor of Political Science and International Studies, University of Tampa. 